\title{
TUHAN DALAM PANDANGAN FILOSUF (Studi Komparatif Arestoteles dengan Al-Kindi)
}

Edi Sumanto*

\begin{abstract}
Abstrak
Mencoba bebagai ide terhadap eksistensi Tuhan sebenarnya suatu usaha yang paling krusial dan rumit pada kehidupan beragama maupun keyakinan atau percayaan bagi manusia. Berbagai macam cara dan pendekatan sudah dilakukan untuk mencapainya oleh para teolog, pemikir, dan ilmuwan, termasuk para filosuf dengan berbagai cara dan pendekatan demonstratif Filosofisnya. Alasan-alasan selaku argumen yang disponsori oleh Aristoteles adalah salah satu yang sangat terkenal dan sudah diambil juga disebarluaskan oleh para filosuf sesudahnya, tak terkecuali alasanalasan tentang Tuhan yang disampaikan oleh lain sesudahnya, ikut mempengaruhi pemikiran mereka tentang Tuhan, akan tetapi filosuf muslim Al-Kindi mempunyai pendapat yang berbeda yang disesuaikan agama yang dianutnya.
\end{abstract}

Kata Kunci: Tuhan, Arestoteles, Al-Kindi

\section{Pendahuluan}

Sudah diketahui kebanyakan manusia bahwa kepercayaan terhadap Tuhan tidaklah bertentangan pada keberadaan manusia, sebab semua indivvidu manusia mempunyai pengalaman-pengalaman tentang agama dan mempunyai hal-hal yang trasenden di dunia. Jika mau disebutkan percaya dengan Tuhan sangat tepat sekali dengan eksistensi manusia, Sebab itulah didalamnya ada hal-hal yang ril melebihi kenyataan yang ada didunia. Sudah banyak para filosuf yang mencoba pendapatnya dan menghadirkan berbagai macam fakta atau bukti yang bisa masuk akal (bersifat rasional). Fakta atau bukti tersebut sering disebut oleh para filosuf menyebutnya dengan eksistensi sebab pada inti tujuannya akhirnya dapat menjawab pertanyaan yang berhubungan dengan akal budi sehingga fakta atau bukti eksistensial menjawab keperluankeperluan yang ada pada manusia secara keseluruhan, selaku eksisensi. Faktafakta/bukti rasional lebih bersifat objektif maka bukti tersebut lebih bersifat ilmiah selaku ilmu menuntut dilakukan pemikiran-pemikiran yang objektif agar dapat diterima selaku pernyataan. ${ }^{1}$

Bedasrkan alasan diatas, bahwa dalam pencarian bukti tentang tuhan 
perlu dibuktikan secara ilmiah, selaku tuntutan darii lmu, dengan demikian manusia dapat menerimanya selaku penciptanya dan mengatahui makna dan eksistensi tentang Tuhan.

\section{A. Biografi Arestoteles}

Aristoteles merupakan murid dari Plato, dia seorang yang diberikan pengajaran yang baik sebelum jadi filosof. Keluarganya yaitu tergolong hobi terhadap ilmu kedokteran, bapaknya seorang dokter pribadi raja Macedonia Amyntas. Cara berfikir sientific ini sangat besar masuk pada pribadi Aristoteles. Sebab itu, orang yang membaca dan mempelajarinya bisa melihat filsafat Aristoteles berbeda pemikirannya pada filsafat Plato yang sistematis dan begitu dipengaruhi oleh metode empiris. Ia juga banyak mempelajari filsafat, matematika, astronomi, retorika, dan ilmu-ilmu lainnya. Dengan kecemerlangan otaknya, ia hampir menguasai macam-macam ilmu yang ada pada zamannya. ${ }^{2}$

Aristoteles ialah fiolsuf besar Yunani terakhir juga sangat besar pengaruhnya. Lahir pada tahun 384 SM di Stagyra, suatu kota di wilayah thrace Yunani Utara. Orangtuanya wafat suatu dia masih sangat muda. Dia diasuh oleh Proxenus, dan orang ini mengajarkan pendidikan yang exlusive terhdapnya. Sewaktu
Aristoteles berumur kira-kira 18 tahun, dia disuruh ke Athena dan belajar ke Akademia Plato, kurang lebih selama 20 tahun hingga Plato meninggal. Pada waktu itu suatu kelaziman para orangtua memasukkan anak-anaknya ke daerah yang jauh karena tempat tersebut yang merupakan sentral berkembangnya intelektual. ${ }^{3}$

Pada kalangan pergaulan papan atas, Aristoteles dapat dibilang lebih sukses dibandingkan Plato, sesudah Plato wafat, Aristoteles dengan teman-temannya Xenokrates pergi dari Athena, sebab dia kurang senang terhadap pemikiran Plato di Akademia yang berhubungan pada filsafat. Sewaktu sampai di Assos, Aristoteles dan temantemannya mengajar disekolah phythia. Pada 345 SM kota Assos diserbu oleh tentara Persia, rajanya (teman Aristoteles) dibunuh, selanjutnya Aristoteles bersama teman-temannya meninggalkan kota tersebut, dan pergi ke Mytilene di pulau Lesbos, dia berdekatan dengan Assos. Tahun 342 SM, Aristoteles diundang Raja Philippos dari Macedonia supaya mengajari anaknya Alexander Agung. ${ }^{4}$

Aristoteles memiliki pengaruh yang luar biasa kepada sejarah dunia, Alexander bukan saja mendapatkan semua idea dan rencananya, namun juga bersama pemikiraannya. Antara tahun 
340-335 SM Aristoteles menekuni riset di Stagira, dibantu oleh Theophratus yang juga tamatan Athena. Riset yang intensif itu ditanggung biayanya oleh Alexander, dan mendapatkan hasil perkembangan dalam Sains dan filsafat. ${ }^{5}$

Pada tahun 334 SM Alexander berperang di Asia, waktu itu Aristoteles kembali ke Athena, bukan selaku murid, tetapi dia membangun lembaga sekolah yang diberi nama Lyceum. Sehingga terjadi persaingan sengit diantara Lyceum dan Akademi. Persaingan sekolah tersebut membuat dorongan Aristoteles guna lebih meningkatkan risetnya, hasilnya ia bukan saja bisa menerangkan prinsip-prinsip Sains, akan tetapi dia juga memberi pelajaran politik, retorika, dan dialektika.

Penduduk-penduduk Athena yang benci pada Macedonia melihat Aristoteles selaku penyebar pengaruh yang bersifat subversif dan dituduh selaku pribadi yang atheis, sebab itu dia berfikir sangat bijak sehingga pergi dari Athena. Selanjutnya dia hijrah ke Chalcis dan wafat disana pada tahun 322 SM. Dia mengalami banyak kehilangan karangan atau tulisannya, Untung saja ada yang masih dapat menerangkan bahwa dia pribadi yang ulet dalam bekerja. Tuliannya tentang logika yang bernama Organon yang isinya tentang chategories. Beberapa bukunya diantaranya $\mathrm{On}$ Interpretation yang menulis macam-macam tipe proposisi, Prior Analyticsyang membicarakan Silogisme, Posterior Analytics yang menyebutkan keterangan ilmiah yang berhubugan tentang pengetahuan sains maupun hal lainnya.

Masuk tahun 323 SM Alexander Agung wafat. Masalah tersebut, menimbulkan suatu gerakan Anti Macedonia oleh kota-kota yang ada keinginan memisahkan diri terhadap cengkaraman dari kerajaan Macedonia, diantaranaya yaitu Athena. Disebabkan oleh kedekatan Aristoteles terhadap Raja Alexander Agung, maka dia anggap berpihak padanya. Dengan timbulnya pemberontakkan tersebut. Aristoteles dengan berat hati keluar dari Athena dan memberikan Sekolah Lykeion kepada muridnya Theopratos. Kemudian Aristoteles berangkat menuju Khalkis, tempat asal ibunya. Dia berdiam ditempat itu sampai akhirnya dirinya sakit dan sampai wafatnya diumur 62 tahun. ${ }^{6}$

Ulasan tersebu yang berhubungan pada pembahasan dari biografi Arestoteles secara singkat,memberikan pengetahuan kepada kita, tentang perjalanan hidupanya, sehingga 
membahas karyanya berdasarkan informasi yang tepat.

\section{B. Biografi Al-Kindi}

Al- Kindi bin Ishaq atau nama legkapnya Al-Kindi bin Abu Yusuf Ya'qub bin Ishaq. Al-Kindi adalah seorang ilmuan dan filosuf terkenal Islam yang hidup pada pemerintahan kekhalifahaan Bani Abbasiyah. Dia dilahirkan tahun 809 $\mathrm{M}$ dan meninggal pada tahun 873M. Dia mempunyai garis keturunan suku Kindah, yang merupakan suku besar di Arab Selatan pada masa sebelum Islam. Keluarga Al-Kindi merupakan keluarga terpandang sebab strata sosialnya tinggi. Orang tuanya pernah menjabat selaku gubernur Kufah pada masa kekhalifahan Al-Mahdi (775-778M) dan kekhalifah ArRasyid (786-809M). ${ }^{7}$ Dunia mengetahui Al-Kindi selaku penggerak atau pelopor dari ilmu pengetahuan. Hal tersebut disebabkan karya dan pemikiran Al-Kindi mencakup bidang yang begitu luas dan beragam. Hampir mencakup semua bidang keilmuan, pasti ada karya Al-Kindi yang mengomentarinya ataupun menjelaskannya. Pertamakali Al-Kindi belajar, merupakan daerah di Iraq yang menjadi sentral pengetahuan dan pertemuan intelektual dunia, akantetapi akhirnya dia menamatkan belajarnya di kota Bagdad. Sekarang ini merupakan pusat atau Ibukota Iraq. Al-Kindi bertemu kepada rombongan pangeran Abbasyiah, yaitu Al-Ma'mundan Al-Mu'tasim. Kemudian Al-Kindi diajak dan dijadikan guru private Ahmad, putra Al-Makmun yang membuatnya dapat dorongan atau bantuan kuat untuk mengeluarkan karangan-karangan yang besar dibidang ilmu pengetahuan. Al-Kindi hidup semasa kekuasaan Bani Abbasyiah, seperti AlAmin (809-813M), Al-Ma'mun (813-833M), Al-Mu'tasim (833-842M), Al-Watsiq (842847M), dan Al-Mutawakil (847-851M). Selama masa tersebut, Al-Kindi banyak mengeluarkan karangannya dibidang filsafat, matematika (geometri), agama, asrtonomi, logika dan kedokteran. Seperti hasil karya al-Kindi yang ikut menghiasi khasanah dunia pengetahuan yaitu Risalah fi masail suila 'anha min ahwal al-kawakib (jawaban dari pertanyaan-pertanayaan planet), risalah fi mathrah asy-syu'a (tentang projeksi sinar), dan risalah fi idhah 'illa ruju' al-kawakib (yang berhubungan pada keterangan sebab gerak kebelakang planet-planet). Dari sekian banyaknya ilmu yang ada dia paling suka menghargai matematika, hal itu dikarenakan matematika oleh Al-Kindi adalah suatu pembuka bagi setiap orang yang berkeinginan belajar bidang filsafat. Mukadimah atau pembuka tersebut begitu sangat urgen yang menjadikan bagi 
siapa saja, untuk dapat menguasai atau mempelajari filsafat harus mengetahui matematika terleih dahulu sebagi pintu masuk. Matematika disini mencakup berbagai ilmu yang berhubungan pada bilangan, harmoni, geometri, dan astronomi. Namun dianggap begitu utama kesemua bidang matematika tersebut, yaitu ilmu bilangan atau aritmatika sebab kalau bilangan tidak ada, maka tidak akan ada sesuatu apapun. ${ }^{8}$

Al-kindi merupakan filosuf keturunan Arab dan dinilai selaku filosuf muslim pertama. Diantara karyanya yang membuat ciri khas yang menjadikan suatu kelebihan, seperti menghadirkan filsafat Yunani terhadap umat muslimin sesudah terlebih dahulu menyesuaikan atau mengislamkan pemikiran-pemikiran filsafat Yunani yang ada.

\section{Tuhan dalam Pandangan Arestoteles}

Aristotelesberanggapan bahwa

Tuhan yaitu penggerak alam. Dalam teori actus potensi alam merupakan objek yang mempunyai potensi dalam melaksanakan perubahan. Perubahan tersebut, maksudndnya merupakan tujuan. Dengan istilah lain, alam mempunyai potensi dalam merealisasikan dirinya sesuai dengan tujuannya. Tujuan dari semua objek yang adapada alam semesta

$$
\text { yaitu actus }
$$

purus, yaitu Tuhan. ${ }^{9}$ Sedang dalam pendapat Harun Nasution yang dikemukakan oleh Arestoteles Tuhan merupakan penggerak pertama. ${ }^{10}$

Pendapat Aristoteles, Tuhan berdiri sendiri, tidak beranak, tidak akan berubah, tidak pernah berakhir, dan bersifat kekal. Tuhan merupakan penyebab dari segala benda menjadi bertujuan, akan tetapi bukan sebagai efficient cause, melainkan final cause. ${ }^{11}$ Maksudnya, Tuhan bukan menggerakkan benda secara langsung seumpama halnya memindahkan benda ke tempat yang tidak sama atau berbeda, namun memberikan tujuan final atau arah akhirnya. Proses untuk sampai final yaitu cara masing-masing benda. Dengan demikian, bagaimanapun cara alam seluruh isinya bergerak dan merealisasikan dirinya tujuan akhirnya tetap actus purus. Menurut Aristoteles, dalam proses perubahan yang bergerak dari materi menuju forma, mengandaikan adanya forma terakhir yang tidak dapat “dikeruhkan" lagi dengan materi (tidak bisa menjadi materi yang baru). Inilah forma terakhir (actus purus). Seumpama demikian halnya, maka mesti ada pula penggerak pertama yang tidak digerakkan. Penggerak pertama itu 
merupakan forma yang tak bermateri; tujuan tertinggi yang menyebabkan semua gerak. $^{12}$

\section{Sedangkan Tuhan yang} disampaikan oleh Arestoteles dari Meyer yang dikutif Ahmad Tafsir, menyebutkan bahwa Tuhan hanya ada kaitannya dengan dirinya sendiri. Dia tidak ada kaitan dengan (tidak memperhatikan) alam ini.Dia bukan pesona, dia tidak memperdulikan doa ataupunkemauan manusia. Dalam mencintai Tuhan manusia, janganlahada harapan dia mencintainya. Dia merupakan kesempurnaan tertinggi, dan kita mencontoh kesana untuk perbuatan dan pikiran-pikiran kita. ${ }^{13}$

Pendapat di atas, mempunyai makna dalam pengertianTuhan yang disampaikan oleh Arestoteles, yaitu bahwa Tuhan merupakan penggerak pertama bagi kehidupan di alam ini, pendapat lainnya mengatakan bahwa Tuhan hanya berhubungan terhdap dirinya sendiri, dan dia tidakada kepudulian terhadap alam, dan manusia. Sehingga manusia jangan terlalu berharap darinya dalam berdoa. Namun yang jelas pendapat ini hanya berdasarkan pemikiran semata dari Arestoteles yang tidak ada rujukandengan kitab Tuhan.

\section{Konsep Tuhan dalam Pandangan Al-} Kindi

Tuhan dalam pandangan Al-kindi yang dipahami atau analisa oleh Harun Nasution yaitu pencipta bukan penggerak pertama seperti yang dikemukakan oleh Arestoteles. ${ }^{14}$ Sedangkan pemahaman Tuhan dalam Filsafat Al-Kindi tampak pada tulisannya yang diberikan sebagai hadiah kepada Ahmad bin Al Mu'tashim Billah berkaitan pada filasafat pertama. Kesimpulan risalah/tulisan tersebut, Alkindi mengungkapkan: Dialah Yang Pertama, Pencipta yang menguasai semua makhluknya, Tuhan ialah yang menjadikan langit dan bumi beserta isinya, ${ }^{15}$ suatu yang lepas dari kekuasaannya yaitu durhaka dan pasti hancur. ${ }^{16}$

Untuk pembuktian adanya Allah, Al-Kindi mempunyai, tigacara, yaitu: Baharunya alam, keanekaragaman dalam wujud (katstrah fil mujudat), dan kerapian/keharmonasan alam. ${ }^{17}$ Agar menjelaskannya lebih dapat dipahami pertama Al-Kindi dimulai dengan cara pada bentuk suatu pertanyaan, seperti, mungkinkah sesuatu itu menjadi sebab bagi wujud darinya atau kah tidak mungkin?. Kemudian ia menjawabnya 
sendiri bahwa, hal itu tentulah tidak mungkin sebab akal tidak bisa menerimanya jika sesuatu menciptakan ataupun menjadikan dirinya sendiri, hal tersebut menunjukkan bahwa alam ini adalah baharu (muhdas) dan memiliki awal waktu sebabalum ini terbatas. Kemudian cara kedua bahwa alam ini tentu ada penyebab terjadinya karena tidak mungkin ada benda terjadi dengan sendirinya, untuk cara ketiga yaitu jalan kerapian Al-Kindi mengungkap kan bahwa alam lahir tidak mungkin rapi dan teratur kecuali karena adanya zat tidak kelihatan, zat yang tidak kelihatan tersebut hanya bisa diketahui dengan melalui bekas-bekas-Nya dan kerapian yang terdapat dalam alam ini. ${ }^{18}$

Keterangan yang disampaikan oleh Al-kindi tentang Tuhan di atas, berdasarkan pemikirannya, dan sesuai juga menurut ajaran islam yang termuat dalam Al-qur'an.

\section{E. Kesimpulan}

Di dalam filsafat ketuhanan pada pandangan Arestoteles menyatakan bahwa seluruh kenyataan bergerak antara dua kutub abstrak yaitu materi yang tak berbentuk dan forma yang tak bermateri. Disinilah yang bisa disebut Tuhan. Tuhan tersebut bukan bentuknya rmateri, tetapi realitas saja. Ia juga roh murni (nous); pikiran semata. Ia tidak dapat memikirkan dunia; hanya memikirkan dirinya sendiri. Dan dia puas dengan dirinya sendiri, tidak mempunyai korelasi sedkitpun pada dunia. Aristoteles sedikitpun tidak mengenal Tuhan yang menjadikan langit dan bumi. Tuhannya merupakan Tuhan para filosuf dan bukanTuhannya para nabi.

Sedangkan

Al-Kindi, mengungkapkan bahwa Tuhan merupakan wujud yang sesungguhnya, bukan berasal dari sesuatu tidak ada menjadi ada. Allah tidak mungkin tidak ada dan selamanya ada dan akan tetap selalu ada . Allah merupakan wujud yang sempurna dan tidak didahului wujud lain. 


\section{Referensi}

${ }^{1}$. Theo Huijbers, Mencari Allah Pengantar Kedalam Filsafat Ketuhanan,(Yogyakarta: Kansius, 1995), h. 115.

2. Ali Maksum, Pengantar Filsafat, (Yogyakarta: 2008), h.81

Hati.., h. 60

3. Ahmad Tafsir, Filsafat Umum Akar dan

${ }^{4}$. Ahmad Tafsir, Filsafat Umum Akar dan Hati.., h. 81

5. Ahmad Tafsir, Filsafat Umum Akar dan Hati.., h. 59-60

6. Muzairi, Filsafat Umum, (Yogyakarta:

Teras, 2009), h. 6

KajianKeislamanNurulIImi,bukuindukterlengkap agama islam, (Jakarta: Citra Risalah, 2012

${ }^{8}$. Ahmad ZainulHamdi, TujuhFilsuf Muslim PembukaPintuGerbangFilsafat Barat Modern, Yogyakarta: PustakaPesantren, 2004, cet. 1, h. 47.

${ }^{9}$. Hadiwijono, Harun, Sari Sejarah Filsafat

Barat 1, (Yogyakarta: Penerbit Kanisius, 2005), h. 51

HarunNasution,

FilsafatdanMistisismedalam Islam, (BulanBintang, Jakarta, 1990), h. 71

11.

https://www.apaitu.net/2010/1684/aristoteles-

tentang-tuhan-alam-berdasarkan-actus-potensi/

diakses hari Rabu, tanggal 2 Mei 2018

${ }^{12}$.https://pormadi.wordpress.com/2006/05/1

7/konsep-tuhan-menurut-aristoteles/, diakses, kamis 26 April 2018

${ }^{13}$. Ahmad, Tafsir,Filsafat Umum, (Bandung: Rosdakarya, 2012), h. 61

${ }^{14}$. Dedi Supriyadi, Pengantar Filsafat Islam

Konsep Filsuf, dan Ajarannya,Bandung:Pustaka Setia, 2009), h. 56

${ }^{15}$. Ahmad Fuad Al-Alhwani, Filsafat Islam, terj Sutarji Caulzoum Bakhri,( Jakarta: Pustaka Firdaus, 1985), h. 54-55

16. Ahmad Fuad Al-Alhwani, Filsafat Islam....h. 102

17 . Ahmad Hanafi, PengantarFilsafat Islam, ( Jakarta:BulanBintang, 1991), Cet. V, h. 17

${ }_{18}$. H.M. Rasyidi, Islam untukDisiplinIlmuFilsafat,(Jakarta:BulanBintang, 1980), h. 9 